\title{
A Facile Synthesis of Granular ZnO Nanostructures for Dye-Sensitized Solar Cells
}

\author{
Md. Mahbubur Rahman, ${ }^{1}$ Narayan Chandra Deb Nath, \\ Kwang-Mo Noh, ${ }^{2}$ Jaecheon Kim, ${ }^{3}$ and Jae-Joon Lee ${ }^{1,3}$ \\ ${ }^{1}$ Department of Advanced Technology Fusion, Konkuk University, Seoul 143-701, Republic of Korea \\ ${ }^{2}$ Nanotechnology Research Center and Department of Nano Science and Mechanical Engineering, Konkuk University, \\ Chungju 380-701, Republic of Korea \\ ${ }^{3}$ Nanotechnology Research Center and Department of Applied Chemistry, Konkuk University, Chungju 380-701, Republic of Korea
}

Correspondence should be addressed to Jae-Joon Lee; jjlee@kku.ac.kr

Received 15 February 2013; Accepted 5 April 2013

Academic Editor: Theodoros Dimopoulos

Copyright (C) 2013 Md. Mahbubur Rahman et al. This is an open access article distributed under the Creative Commons Attribution License, which permits unrestricted use, distribution, and reproduction in any medium, provided the original work is properly cited.

Granular $\mathrm{ZnO}$ nanostructures of single-crystalline wurtzite hexagonal phases were synthesized by a facile and low-cost chemical method in aqueous condition. The average size of $\mathrm{ZnO}$ nanograin increased with reflux time, and it significantly affected the open circuit potential $\left(V_{\mathrm{oc}}\right)$ while the short circuit current density $\left(J_{\mathrm{sc}}\right)$ was not changed much. The overall energy conversion efficiency was $1.82 \%$ with the smaller grain size of $c a .250 \mathrm{~nm}$ when it was used as photoelectrode of DSSCs. The positive shifting of the Fermi energy $\left(E_{\mathrm{F}}\right)$ and low density of surface states (DOS) were consistent with the reduction of the recombination of excited electron with electrolyte for smaller grains.

\section{Introduction}

Zinc oxide $(\mathrm{ZnO})$ is unique in exhibiting both semiconducting and piezoelectric properties [1]. Bulk $\mathrm{ZnO}$ is a direct and a wide band gap semiconductor $\left(E_{g} \sim 3.2 \mathrm{eV}\right.$ at $\left.25^{\circ} \mathrm{C}\right)$ with high excitation binding energy $(\sim 0.06 \mathrm{eV})$, large saturation velocity $\left(3.2 \times 10^{7} \mathrm{~cm} \mathrm{~s}^{-1}\right)$, and high optical gain $\left(300 \mathrm{~cm}^{-1}\right)$ [2]. The high excitation binding energy leads to excitonic transitions $\left(\sim 25^{\circ} \mathrm{C}\right)$, high radiative recombination efficiency for spontaneous emission, and a low threshold voltage for laser emission. The quantum confinement effect of photogenerated electron-hole pairs and the tunability of optical and electronic properties of $\mathrm{ZnO}$ nanoparticles $(\sim 10 \mathrm{~nm})$ $[3,4]$ allowed them to be used in various nanodevices such as information storage, sensing, and surface acoustic wave devices [5-7].

$\mathrm{ZnO}$ is potentially useful in dye-sensitized solar cells (DSSCs) because it has a similar band gap to $\mathrm{TiO}_{2}$ and shows lower electron-hole $\left(\mathrm{e}^{-}-\mathrm{h}^{+}\right)$recombination probability due to its filled valence band $\left(E_{\mathrm{VB}}\right)\left(3 d^{10}\right)$ and $s-p$ hybridization properties of conduction band $\left(E_{\mathrm{CB}}\right)$ [2]. The less population of deep traps in $\mathrm{ZnO}$ nanostructures compared with $\mathrm{TiO}_{2}$ nanoparticles induced the longer electron lifetime [2]. In spite of these superior physical properties of $\mathrm{ZnO}$, the photoconversion efficiency of $\mathrm{TiO}_{2}$-based DSSC is generally much higher than $\mathrm{ZnO}$. This was mainly attributed to the acidity of the binding groups of dyes (e.g., N719, N3, and black dyes, etc.), which reduced the chemical stability of $\mathrm{ZnO}$ by dissolving it to form a precipitation of dye- $\mathrm{Zn}^{2+}$ complexes to lead electron injection and dye regeneration inefficiently [8]. In general, it is known that nanostructures, such as nanorods, nanofibers, and nanowires, induce less recombination to improve the charge collection efficiency [9-11]. This work reports the synthesis of granular $\mathrm{ZnO}$ nanostructures by simple hydrothermal reactions of zinc nitrate and $\mathrm{KOH}$ in the presence of tetra butyl ammonium hexafluorophosphate $\left(\mathrm{TBAPF}_{6}\right)$. The effects of the size of $\mathrm{ZnO}$ nanograin on the photovoltaic performances of DSSCs were studied in conjunction with their morphology as well as the optical and the electronic properties. 


\section{Experimental}

Zinc nitrate $\left[\mathrm{Zn}\left(\mathrm{NO}_{3}\right)_{2} \cdot 6 \mathrm{H}_{2} \mathrm{O}\right](0.01 \mathrm{~mol})$ and $\mathrm{KOH}$ $(0.02 \mathrm{~mol})$ were dissolved in $20 \mathrm{~mL}$ of distilled water to form a white flocculate, which was then diluted to $100 \mathrm{~mL}$. After the addition of $5 \times 10^{-3} \mathrm{~mol} \mathrm{TBAPF}_{6}$ while stirring, it was refluxed for 30,60 , and $120 \mathrm{~min}$ to obtain white precipitates. The samples, being collected by centrifuge and dried for 30 hours at room temperature after washing with water and ethanol, were sintered in an electric muffle furnace at $500^{\circ} \mathrm{C}$ for $30 \mathrm{~min}$ in ambient condition before further characterization. They were denoted as $\mathrm{Z1}, \mathrm{Z} 2$, and $\mathrm{Z} 3$, respectively, depending on the reflux time.

Scanning electron microscopy (SEM, Hitachi S-3000N, Japan) was used to investigate the $\mathrm{ZnO}$ nanograin's surface morphologies. X-ray diffractometry (Philips, X'pert, Netherland) was conducted using $\mathrm{Cu} \mathrm{K}_{\alpha}$ radiation $(\lambda=0.15406 \mathrm{~nm})$ over a $2 \theta$ scan range of $20^{\circ}-80^{\circ}$. Optical absorption and photoluminescence emission spectra of the $\mathrm{ZnO}$ dispersed in ethanol were obtained using a UV-Vis spectrophotometer (Scinco, S-3100, Republic of Korea) and spectrofluorometer (Horiba, Flourolog-3, USA). The amount of dye adsorptions on photoelectrodes was measured from the absorption spectra of desorbed-dye solutions as reported in the literature [12].

$\mathrm{ZnO}$ paste was prepared by mixing $\mathrm{ZnO}$ powder, which was pretreated by acetyl-acetone to minimize aggregation with ethanol, terpineol, and $10 \%$ ethyl cellulose as reported elsewhere $[10,11]$. The $\mathrm{ZnO}$ films on FTO (Pilkington, $8 \Omega / \mathrm{sq}$ ) were prepared by doctor blading and were sintered in an electric muffle furnace at $500^{\circ} \mathrm{C}$ under ambient condition. They were immersed in ethanolic solution of $0.4 \mathrm{mM}$ cis-diisothiocyanato-bis (2,2' -bipyridyl$4,4^{\prime}$-dicarboxylato) ruthenium(II) bis-tetrabutylammonium (N719) for $12 \mathrm{~h}$. Counter electrodes were prepared by spin coating of $5 \mathrm{mM}$ chloroplatinic acid hexahydrate $\left(\mathrm{H}_{2} \mathrm{PtCl}_{6} \cdot 6 \mathrm{H}_{2} \mathrm{O}\right)$ in ethanol on FTO and by sintering it in an electric muffle furnace at $380^{\circ} \mathrm{C}$ for $20 \mathrm{~min}$. The dyeloaded photoelectrodes (active area $c a .0 .2 \mathrm{~cm}^{2}$ ) and platinized counter electrodes were sandwiched with $50 \mu \mathrm{m}$ thick surlyn film as a spacer and sealing agent at $110^{\circ} \mathrm{C}$ for $10 \mathrm{~min}$. The electrolyte solution composed of $0.6 \mathrm{M} \mathrm{1,2-dimethyl-3-}$ propylimidazolium iodide (DMPII), 0.1 M LiI, $0.1 \mathrm{M} \mathrm{I}_{2}$, and $0.5 \mathrm{M}$ 4-tert-butylpyridine ( $t \mathrm{BP})$ in 3-methoxypropionitrile (MPN) was injected into the cell through the drilled holes on the counter electrode. They were sealed with a transparent scotch tape for temporal sealing.

An AM1.5 solar simulator with a $200 \mathrm{~W}$ Xenon lamp (Polaronix K201, McScience, Republic of Korea) was used to illuminate the cells, whose current density-voltage $(J-V)$ properties were measured using a photovoltaic power meter (Polaronix K101 LAB20, McScience, Republic of Korea). The incident light intensity was adjusted to $100 \mathrm{mWcm}^{-2}$ (1 sun) by a standard mono-Si solar cell (PVM 396, PV Measurement Inc., USA) certified by the US National Renewable Energy Laboratory. Cyclic voltammetric (CV) experiment was performed with a CHI430A electrochemical workstation ( $\mathrm{CH}$ instruments, Inc., USA). ZnO nanograins on FTO, a platinum wire, and a $\mathrm{Ag} / \mathrm{Ag}^{+}$electrode were used as working, counter, and reference electrodes, respectively. Electrochemical impedance spectra (EIS) were obtained under open circuit and dark conditions at frequencies of $10^{5}-0.1 \mathrm{~Hz}$ with a $5 \mathrm{mV}$ ac amplitude (IM6ex, Zahner-Elektrik GmbH \& Co. KG, Germany). The measured spectra were fitted to an equivalent circuit appropriate for DSSCs using Zview software (version 3.1, Scribner Associates Inc., USA).

\section{Results and Discussion}

The SEM images showed that the average size of $\mathrm{ZnO}$ nanograins increased slowly with reflux time by reducing the population of smaller size grains, while the aspect ratio (ca. 1.75) was almost unchanged. The lengths of the grains ranged from $c a .50$ to $750 \mathrm{~nm}$, while the upper limit of the grain length was ca. 350, 500, and $750 \mathrm{~nm}$ for Z1, Z2, and $\mathrm{Z3}$, respectively (Figure $1(\mathrm{a})$ ). The XRD patterns of all the synthesized $\mathrm{ZnO}$ nanograins were consistent with the singlecrystalline wurtzite (hexagonal-phase) with no impurities such as $\mathrm{Zn}$ and $\mathrm{Zn}(\mathrm{OH})_{2}$. All the diffraction peaks were well indexed to the hexagonal phase of $\mathrm{ZnO}$ reported in JCPDS card (no. 36-1451) (Figure 1(b)(A)).

All the absorption maxima $\left(\lambda_{\max }\right)$, observed at ca. 362, 376 , and $378 \mathrm{~nm}$ for $\mathrm{Z1}, \mathrm{Z} 2$, and $\mathrm{Z3}$, respectively, were blueshifted relative to the bandgap energy $\left(E_{g}\right)$ of bulk $\mathrm{ZnO}$ [2] with the much broader absorption edges for Z1 (Inset, Figure 1(b)(B)). The lowest value of the $\lambda_{\max }$ of $\mathrm{Z} 1$ indicated the larger $E_{g}$ and the positive shift of quasi-Fermi level $\left(E_{\mathrm{F}, \mathrm{q}}\right)$ compared to those of Z2 and Z3 [13]. Photoluminescence emission spectra, recorded at room temperature under excitation at $350 \mathrm{~nm}$ for $\mathrm{Z} 1$ and $360 \mathrm{~nm}$ for Z2 and Z3, clearly showed the strong UV emissions peaked at ca. $368 \mathrm{~nm}(\mathrm{Z1})$ and ca. $385 \mathrm{~nm}$ (both Z2 and Z3) (Figure 1(b)(B)) which could be attributed to the direct and instant radiative recombination of excitons (RR0) (Scheme 1). The very broad and weak emission observed at $c a .565 \mathrm{~nm}$ for $\mathrm{Z} 1$ was attributed to the other radiative recombination (RR1) through the defect levels possibly caused by vacancies in the interstitial site of zinc and oxygen [14] as described in Scheme 1. Holes form the valence band edge $\left(E_{\mathrm{VB}}\right)$ of $\mathrm{ZnO}$ recombined with electron by tunneling through these defect levels. The significantly low emission intensities in the visible range indicated little density of defect levels for Z2 and Z3 compared with Z1 [15-18]. It indicated that the $\mathrm{Z} 1$ has the high probability of recombination of excitons under UV illumination. Nevertheless, the photoelectrode constructed with $\mathrm{Z} 1$ showed the better performance in DSSCs as shown in the photocurrent density-voltage $(J-V)$ characteristics (Figure 2(a) and Table 1). It was partly because there was no exciton generation in $\mathrm{Z1}$ nanograins during the operation of DSSC and the source of electron was from dyes, which were mostly excited by visible light under AM 1.5 condition. Therefore, the existence of these intrinsic defect levels of $\mathrm{Z} 1$ nanograins did not contribute much to reduce the cell performance because the recombination of these electros was more significantly involved with the highest occupied molecular orbital (HOMO) of dye, which is energetically 

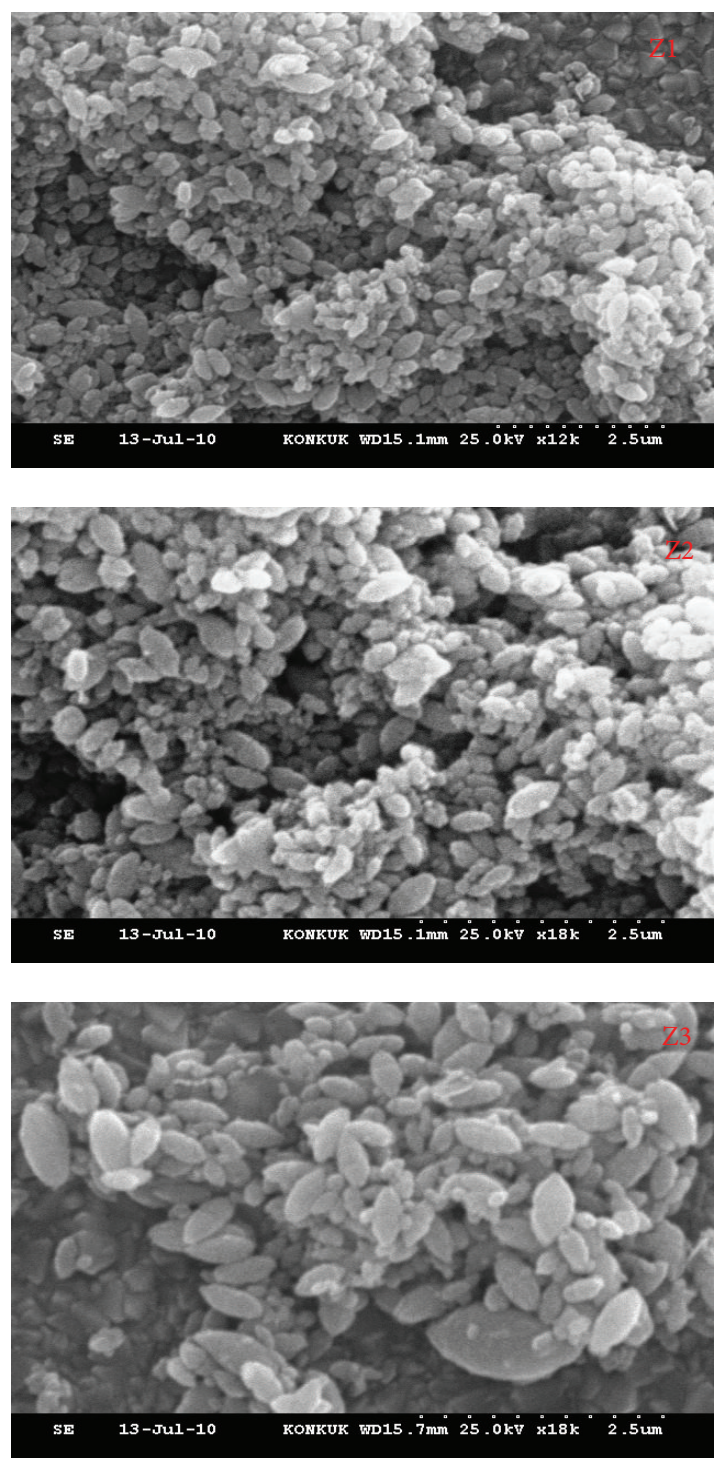

(a)

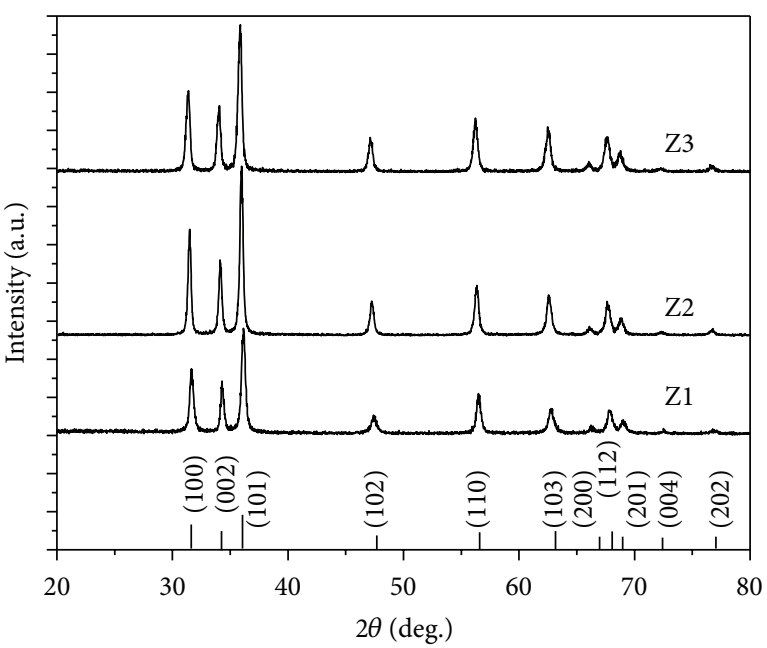

(A)

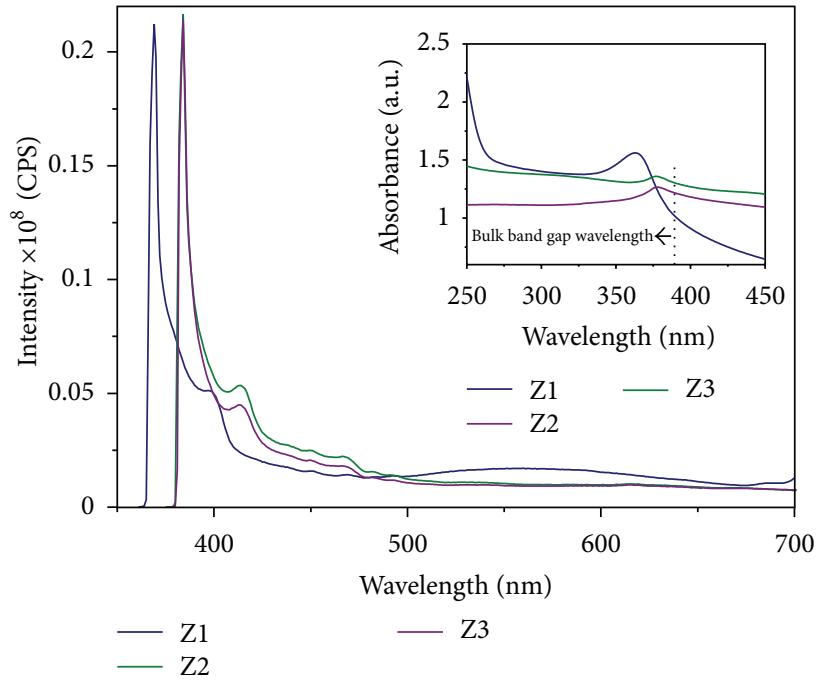

(B)

(b)

FIGURE 1: (a) Scanning electron microscopic (SEM) images (on FTO) and (b) X-ray diffraction (XRD) pattern (A) and photoluminescence spectra in ethanol (inset, the corresponding UV-visible absorption spectra) (B) of Z1, Z2, and Z3 grains.

much more closer to the conduction band edge $\left(E_{\mathrm{CB}}\right)$ of $\mathrm{ZnO}$ than these intrinsic defect levels of Z1 nanograins (Scheme 1).

The overall energy conversion efficiency with Z1 was $c a$. $1.82 \%$ and it was up to $11 \%$ and $15.2 \%$ higher than that of $\mathrm{Z} 2$ and Z3, respectively. The higher efficiency for Z1 was mainly attributed to the higher open circuit potential $\left(V_{\text {oc }}\right)$ compared to Z2 and Z3. Meanwhile, the short circuit current density $\left(J_{\text {sc }}\right)$ was not affected significantly even though the dye loading for Z1 was higher up to $c a .26 .8$ and $41.42 \%$ than those of Z2 and Z3, respectively (Table 1). It could be attributed to the scattering effect with bigger grains [19]. The variation of $V_{\text {oc }}$ in DSSC was known to be dependent significantly on the distribution and density of surface states in the mesoporous structure of photoelectrode, which was investigated by monitoring the nonfaradic capacitive current flow at these electrodes. The capacitive charging current appeared in the forward scans in CVs (Figure 2(b)) could be interpreted as the filling of these surface trap states as previously studied in similar systems based on $\mathrm{TiO}_{2}$ nanoparticles [20-22] and the current essentially reached zero during reverse scans to sufficiently positive potentials because of the regeneration of these surface states by discharging. The higher values of capacitive currents for $\mathrm{Z} 2$ and $\mathrm{Z} 3$ compared to those of the $\mathrm{Z} 1$ indicated the higher density of such trap states as described in Scheme 1. It was found, from the density of states (DOS) calculation [22], that they distributed exponentially with the onset potential being dependent on the size of $\mathrm{ZnO}$ grain (Figure 2(c), Table 1). The downshift of the onset of the 


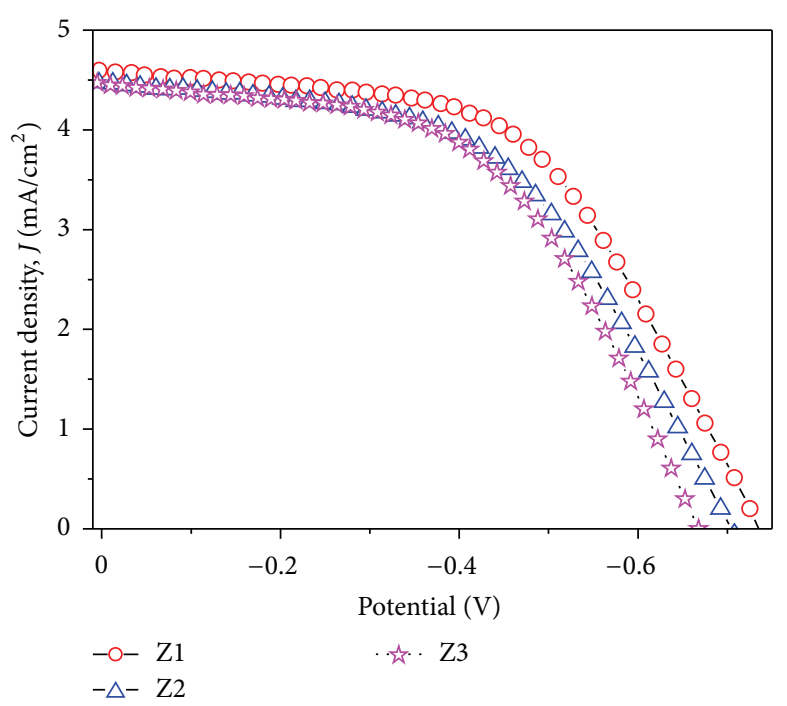

(a)

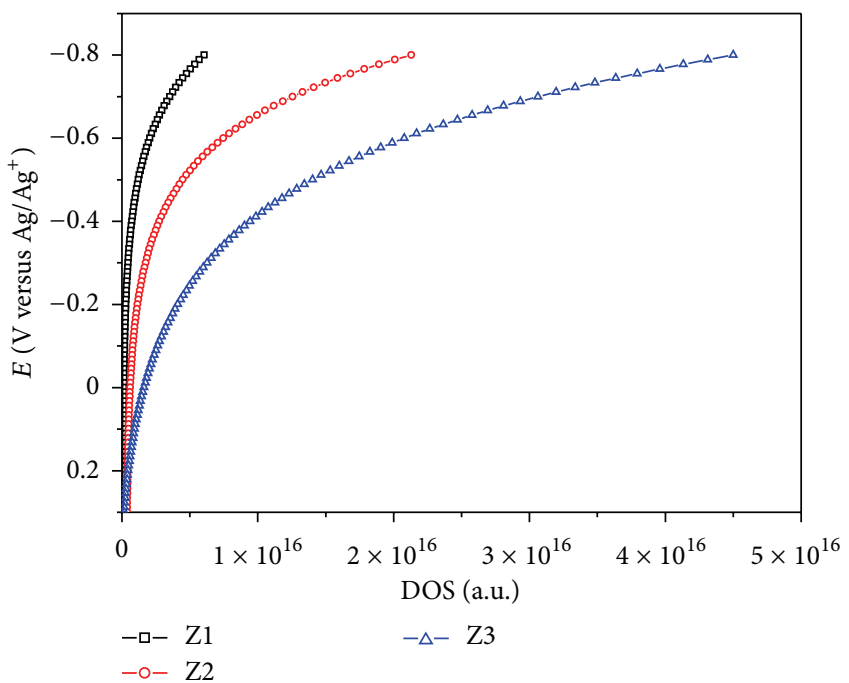

(c)

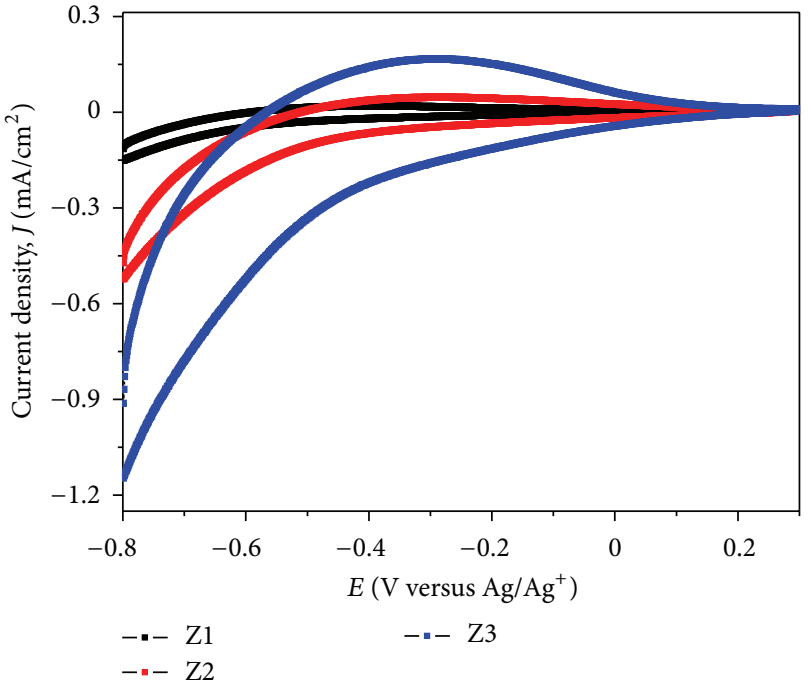

(b)

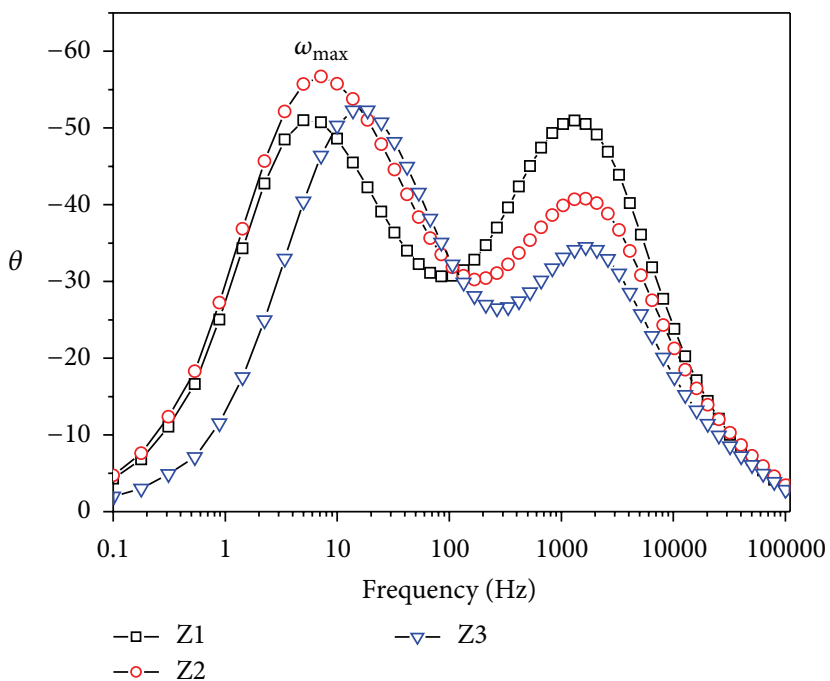

(d)

FIgURE 2: (a) Current density-voltage ( $J$ - $V$ ) characteristics of DSSCs with photoelectrodes of Z1, Z2, and Z3 grains. (b) Cyclic voltammograms $(\mathrm{CVs})$ of the photoelectrodes in $0.5 \mathrm{M} \mathrm{LiClO}_{4}$ dissolved in acetonitrile at a scan rate of $50 \mathrm{mV} / \mathrm{s}$. (c) The exponential distribution of the density of states (DOS) of different $\mathrm{ZnO}$ nanograins was deduced by capacitive charging of electrons into the surface states versus applied potential and (d) the Bode plots from electrochemical impedance spectroscopy of DSSCs.

TABLE 1: Photovoltaic and kinetic parameters of Z1, Z2, and Z3 DSSCs photoelectrodes along with their amounts of adsorbed dye and the onset potential for exponential distribution of the density of states (DOS).

\begin{tabular}{lccccccc}
\hline Electrode & $\begin{array}{c}J_{\text {sc }} \\
\left(\mathrm{mA} / \mathrm{cm}^{2}\right)\end{array}$ & $V_{\mathrm{oc}}(\mathrm{V})$ & $\mathrm{FF}(\%)$ & $\eta(\%)$ & $\begin{array}{c}\text { Adsorbed dye } \\
\left(\mathrm{mol} / \mathrm{cm}^{2}\right)\end{array}$ & $k_{\mathrm{Z} / E}\left(\mathrm{~s}^{-1}\right)$ & $\begin{array}{c}\text { Onset potential } \\
(\mathrm{eV} \mathrm{versus} \mathrm{Vacuum})\end{array}$ \\
\hline $\mathrm{Z} 1$ & 4.6 & 0.73 & 54.08 & 1.82 & $5.77 \times 10^{-7}$ & 5.58 & 4.45 \\
$\mathrm{Z} 2$ & 4.46 & 0.70 & 52.17 & 1.64 & $4.55 \times 10^{-7}$ & 7.10 & 4.76 \\
$\mathrm{Z3}$ & 4.44 & 0.66 & 53.08 & 1.58 & $4.08 \times 10^{-7}$ & 16.85 & 4.87 \\
\hline
\end{tabular}

state distribution was consistent with the tendency of the negative shift of the pseudo-Fermi level of the photoelectrode (Scheme 1) [23], which was responsible for the higher recombination rate to induce the decrease of $V_{\text {oc }}$. The electron transfer kinetics, measured by electrochemical impedance spectroscopy (EIS) at the $\mathrm{ZnO}$ |electrolyte interface under dark condition (Figure 2(d)), was also consistent with this trend by showing the lowest value of the back electron transfer rate to $\mathrm{I}_{3}{ }^{-}\left(k_{Z / E}\right)$ for $\mathrm{Zl}$ as summarized in Table 1. 


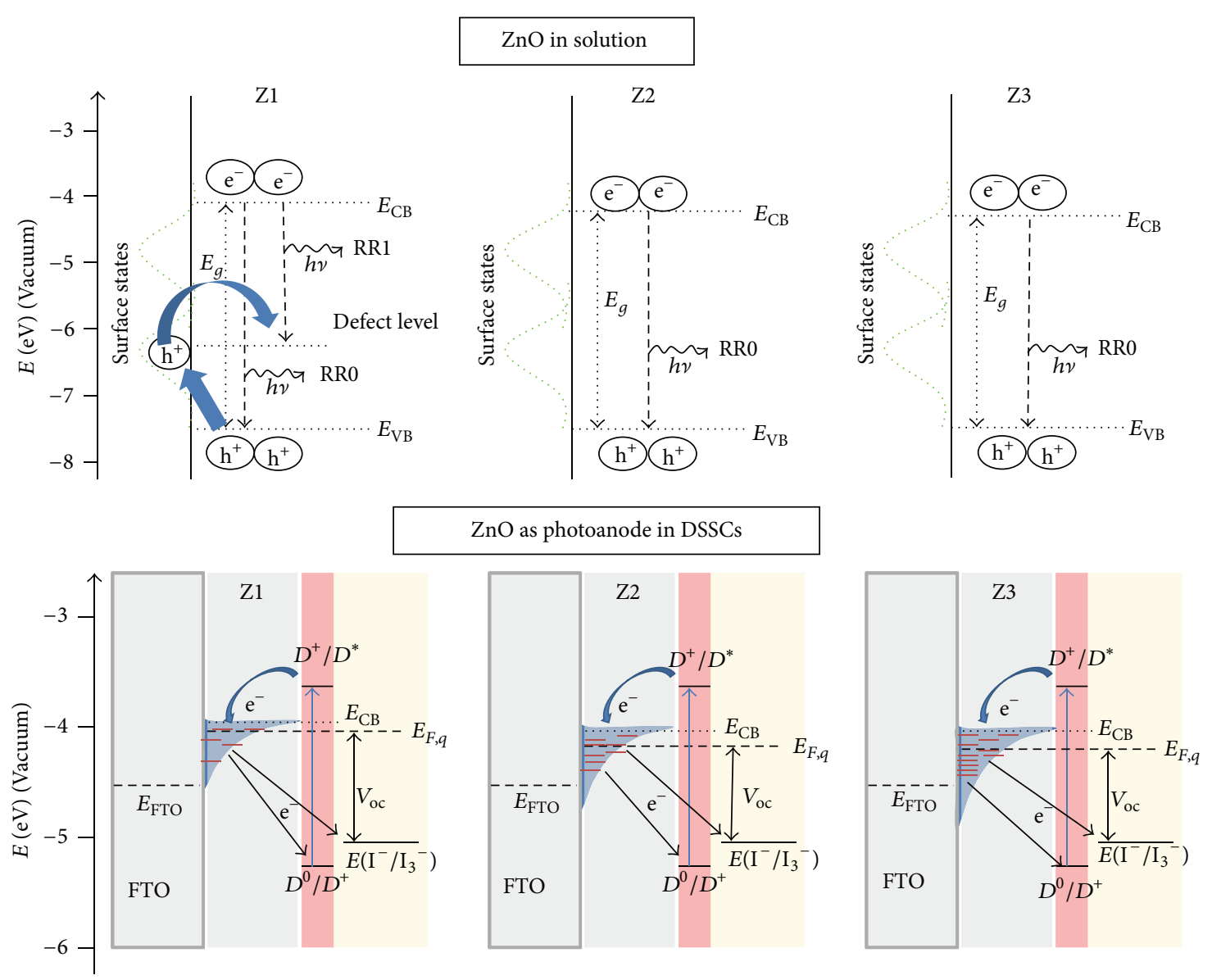

SCHEmE 1: Schematic illustration of the possible relaxation pathways of photoexcited electron in pure Z1, Z2, and Z3 (upper panel) and Z1, $\mathrm{Z} 2$, and Z3 photoelectrodes with energy levels of surface states or traps, dye, and electrolyte in DSSCs (lower panel). RR0 and RR1 and $E_{\mathrm{FTO}}$ are the instant radiative recombination of excitons (RR0), radiative recombination of electron with holes by tunneling through these defect levels (RR1), and the Fermi energy of FTO. The shaded region in the lower panel shows the exponential distribution of the surface states.

\section{Conclusions}

Crystalline $\mathrm{ZnO}$ nanograins being synthesized by a facile hydrothermal method in aqueous system were used as photoanodes in DSSCs. It was found that some physicochemical properties of nanograins such as the density and the distribution of intrinsic defects and surface states were major factors to control many optoelectronic properties such as quasi-Fermi level and radiative recombination probabilities. They were highly dependent on the size of grains and this also affected the performance of DSSCs when used for photoelectrode. Even though the maximum conversion efficiency obtained was $1.82 \%$ with the grain size of ca. $250 \mathrm{~nm}$ (Z1), it showed an improved performance compared with similar previously reported system based on $\mathrm{ZnO}$ nanostructures [24-27]. It was expected that the use of $\mathrm{ZnO}$ nanograin can offer a promising strategy to enhance the performance of DSSCs and further optimization by controlling the size and aspect ratio to enhance the cell performance is still under investigation.

\section{Conflict of Interests}

The authors declare that they have no conflict of interests.

\section{Acknowledgments}

This work was supported by the National Research Foundation of Korea (NRF) grant funded by the government of the Republic of Korea (MEST) (NRF-20100026916) and by the Converging Research Centre Program through the Ministry of Education, Science and Technology (2012K001287) and by Seoul R\&BD Program (WR090671).

\section{References}

[1] B. Wang, S. Nagase, J. Zhao, and G. Wang, "Structural growth sequences and electronic properties of zinc oxide clusters $(\mathrm{ZnO})_{n}(n=2-18)$, , Journal of Physical Chemistry C, vol. 111, no. 13, pp. 4956-4963, 2007.

[2] J. J. Lee, M. M. Rahman, S. Sarker, N. C. Deb Nath, A. J. S. Ahammad, and J. K. Lee, "Metal oxides and their composites for 
the photoelectrode of dye sensitized solar cells," in Composite Materials for Medicine and Nanotechnology, B. Attaf, Ed., pp. 181-210, InTech, Rijeka, Croatia, 2011.

[3] M. Makkar and H. S. Bhatti, "Inquisition of reaction parameters on the growth and optical properties of $\mathrm{ZnO}$ nanoparticles synthesized via low temperature reaction route," Chemical Physics Letters, vol. 507, no. 1-3, pp. 122-127, 2011.

[4] Y. P. Du, Y. W. Zhang, L. D. Sun, and C. H. Yan, "Efficient energy transfer in monodisperse Eu-doped $\mathrm{ZnO}$ nanocrystals synthesized from metal acetylacetonates in high-boiling solvents," Journal of Physical Chemistry C, vol. 112, no. 32, pp. 12234-12241, 2008.

[5] M. M. Rahman, A. J. S. Ahammad, J. H. Jin, S. J. Ahn, and J. J. Lee, "A comprehensive review of glucose biosensors based on nanostructured metal-oxides," Sensors, vol. 10, no. 5, pp. 48554886, 2010.

[6] J. I. Sohn, S. S. Choi, S. M. Morris et al., "Novel nonvolatile memory with multibit storage based on a $\mathrm{ZnO}$ nanowire transistor," Nano Letters, vol. 10, no. 11, pp. 4316-4320, 2010.

[7] V. Chivukula, D. Ciplys, M. Shur, and P. Dutta, "ZnO nanoparticle surface acoustic wave UV sensor," Applied Physics Letters, vol. 96, no. 23, Article ID 233512, 2010.

[8] M. Quintana, T. Edvinsson, A. Hagfeldt, and G. Boschloo, "Comparison of dye-sensitized $\mathrm{ZnO}$ and $\mathrm{TiO}_{2}$ solar cells: studies of charge transport and carrier lifetime," Journal of Physical Chemistry C, vol. 111, no. 2, pp. 1035-1041, 2007.

[9] M. H. Lai, A. Tubtimtae, M. W. Lee, and G. J. Wang, "ZnOnanorod dye-sensitized solar cells: new structure without a transparent conducting oxide layer," International Journal of Photoenergy, vol. 2012, Article ID 497095, 5 pages, 2012.

[10] M. M. Rahman, H. S. Son, S. S. Lim, K. H. Chung, and J. J. Lee, "Effect of the $\mathrm{TiO}_{2}$ nanotubes in the photoelectrode on efficiency of dye-sensitized solar cell," Journal of Electrochemical Science and Technology, vol. 2, pp. 110-115, 2011.

[11] K. H. Chung, M. M. Rahman, H. S. Son, and J. J. Lee, "Development of well-aligned $\mathrm{TiO}_{2}$ nanotube arrays to improve electron transport in dye-sensitized solar cells," International Journal of Photoenergy, vol. 2012, Article ID 215802, 6 pages, 2012.

[12] H. S. Uam, Y. S. Jung, Y. Jun, and K. J. Kim, "Relation of $\mathrm{Ru}(\mathrm{II})$ dye desorption from $\mathrm{TiO}_{2}$ film during illumination with photocurrent decrease of dye-sensitized solar cells," Journal of Photochemistry and Photobiology A, vol. 212, no. 2-3, pp. 122$128,2010$.

[13] N. S. Pesika, K. J. Stebe, and P. C. Searson, "Relationship between absorbance spectra and particle size distributions for quantumsized nanocrystals," Journal of Physical Chemistry B, vol. 107, no. 38, pp. 10412-10415, 2003.

[14] Y. S. Kim and C. H. Park, "Rich variety of defects in $\mathrm{ZnO}$ via an attractive interaction between $\mathrm{O}$ vacancies and $\mathrm{Zn}$ interstitials: origin of $n$-type doping," Physical Review Letters, vol. 102, no. 8 , Article ID 086403, 2009.

[15] T. Tatsumi, M. Fujita, N. Kawamoto, M. Sasajima, and Y. Horikoshi, "Intrinsic defects in $\mathrm{ZnO}$ films grown by molecular beam epitaxy," Japanese Journal of Applied Physics A, vol. 43, no. 5, pp. 2602-2606, 2004.

[16] F. Wen, W. Li, J. H. Moon, and J. H. Kim, "Hydrothermal synthesis of $\mathrm{ZnO}: \mathrm{Zn}$ with green emission at low temperature with reduction process," Solid State Communications, vol. 135, pp. 34-37, 2005.

[17] K. Vanheusden, W. L. Warren, C. H. Seager, D. R. Tallant, J. A. Voigt, and B. E. Gnade, "Mechanisms behind green photoluminescence in $\mathrm{ZnO}$ phosphor powders," Journal of Applied Physics, vol. 79, no. 10, pp. 7983-7990, 1996.

[18] B. K. Sharma, N. Khare, and D. Haranath, "Photoluminescence lifetime of Al-doped $\mathrm{ZnO}$ films in visible region," Solid State Communications, vol. 150, pp. 2341-2345, 2010.

[19] H. Park, W. R. Kim, H. T. Jeong, J. J. Lee, H. G. Kim, and W. Y. Choi, "Fabrication of dye-sensitized solar cells by transplanting highly ordered $\mathrm{TiO}_{2}$ nanotube arrays," Solar Energy Materials \& Solar Cells, vol. 95, pp. 184-189, 2011.

[20] A. Hagfeld and M. Grätzel, "Light-induced redox reactions in nanocrystalline systems," Chemical Reviews, vol. 95, pp. 49-68, 1995.

[21] J. Moser, S. Punchihewa, P. P. Infelta, and M. Grätzel, "Surface complexation of colloidal semiconductors strongly enhances interfacial electron-transfer rates," Langmuir, vol. 7, no. 12, pp. 3012-3018, 1991.

[22] N. C. D. Nath, S. Sarker, A. J. S. Ahammad, and J. J. Lee, "Spatial arrangement of carbon nanotubes in $\mathrm{TiO}_{2}$ photoelectrodes to enhance the efficiency of dye-sensitized solar cells," Physical Chemistry Chemical Physics, vol. 14, pp. 4333-4338, 2012.

[23] J. Bisquert, F. Fabregat-Santiago, I. Mora-Seró, G. GarciaBelmonte, E. M. Barea, and E. Palomares, "A review of recent results on electrochemical determination of the density of electronic states of nanostructured metal-oxide semiconductors and organic hole conductors," Inorganica Chimica Acta, vol. 361, no. 3, pp. 684-698, 2008.

[24] J. B. Baxter and E. S. Aydil, "Nanowire-based dye-sensitized solar cells," Applied Physics Letters, vol. 86, no. 5, Article ID 053114, 2005.

[25] A. Umar, "Growth of comb-like $\mathrm{ZnO}$ nanostructures for Dyesensitized solar cells applications," Nanoscale Research Letters, vol. 4, no. 9, pp. 1004-1008, 2009.

[26] J. J. Wu, G. R. Chen, H. H. Yang, C. H. Ku, and J. Y. Lai, "Effects of dye adsorption on the electron transport properties in $\mathrm{ZnO}$ nanowire dye-sensitized solar cells," Applied Physics Letters, vol. 90, no. 21, Article ID 213109, 2007.

[27] A. Pandikumar, K. M. Saranya, and R. Ramaraj, "Sheaf-like$\mathrm{ZnO} \mathrm{Ag}$ nanocomposite materials modified photoanode for low-cost metal-free organic dye-sensitized solid-state solar cells," Applied Physics Letters, vol. 101, no. 9, Article ID 093112, 2012. 

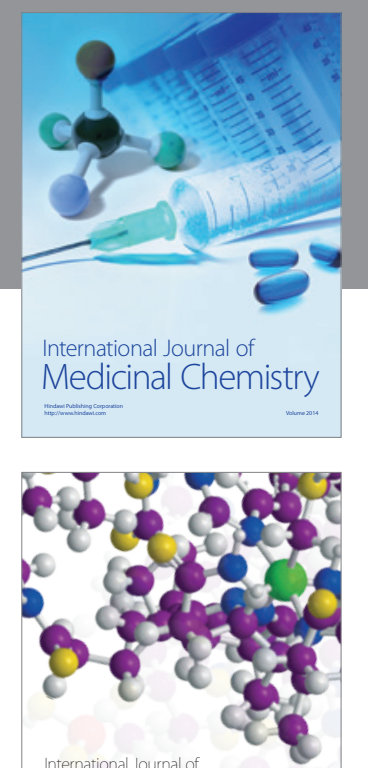

\section{Carbohydrate} Chemistry

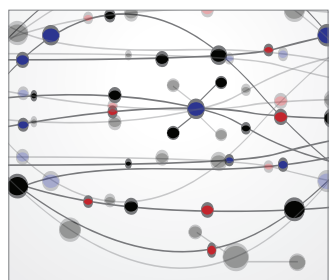

The Scientific World Journal
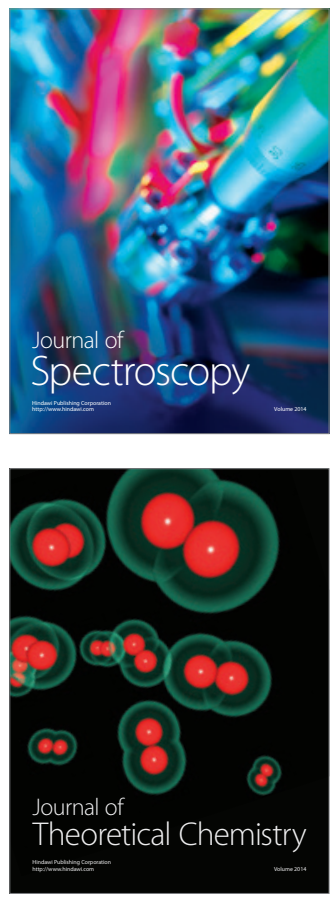
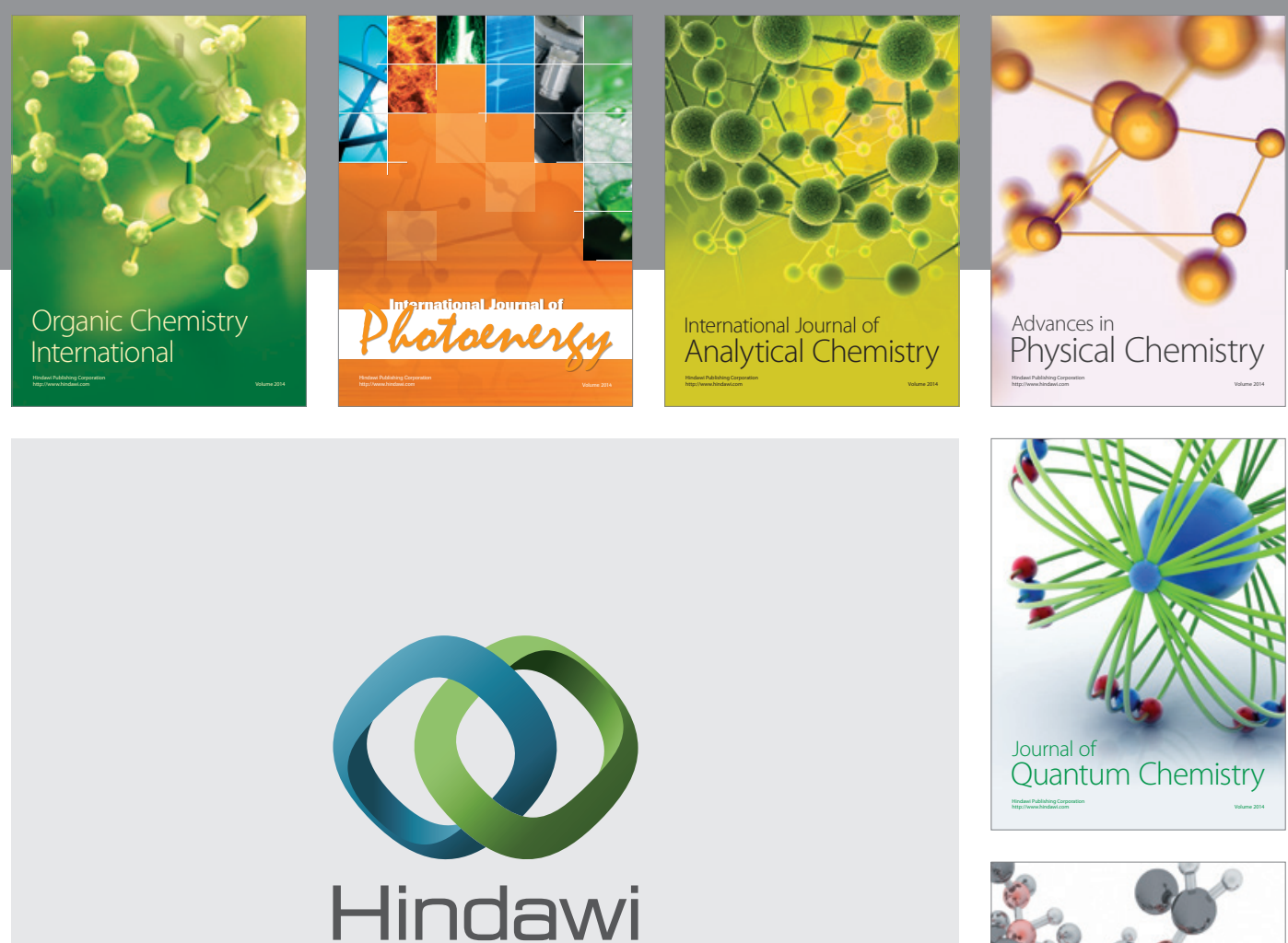

Submit your manuscripts at

http://www.hindawi.com

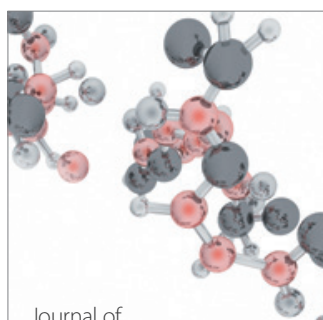

Analytical Methods

in Chemistry

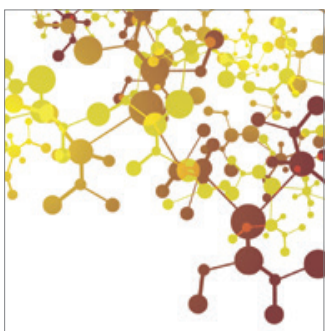

Journal of

Applied Chemistry

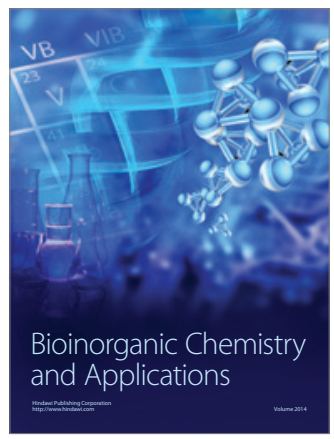

Inorganic Chemistry
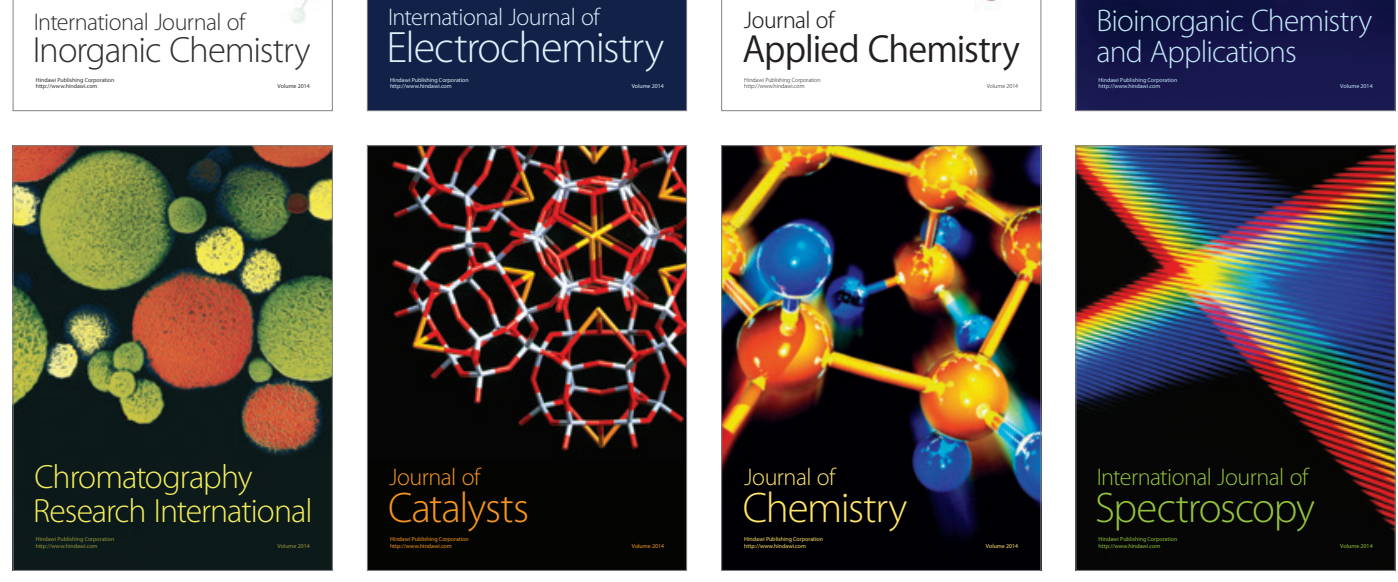